\title{
John Blacking ou uma humanidade sonora e saudavelmente organizada
}

\author{
Elizabeth Travassos
}

\section{Introdução}

John Blacking (1928-1990) integra o relativamente pequeno grupo de autores de referência na etnomusicologia, e seu livro How musical is man? (traduzido para o francês, grego, italiano e japonês) está entre os mais citados nesse campo de estudos, que ele identificou, diversas vezes, como antropologia da música ${ }^{1}$. Sua repercussão é ainda mais ampla, pois How musical is man? (Blacking, 1995b [1973]) é citado também por musicólogos como obra exemplar da "orientaçấo cultural" na abordagem da música (Kerman, 1987, p. 235). Note-se que o prestígio de seu autor se consolidou numa disciplina que, apesar das origens européias, migrou para os Estados Unidos no pós-guerra. Com a fundação da Society for Ethnomusicology em 1955 e a publicação de livros como The anthropology of music (Merriam, 1964), Theory and method in ethnomusicology (Nettl, 1964) e The ethnomusicologist (Hood, 1971), os pesquisadores norte-americanos passaram a ditar os termos do debate relevante na disciplina. John Blacking não apenas estabeleceu na Queen's University of Belfast (Irlanda do Norte) um centro de formação em etnomusicologia que atraiu pesquisadores de todo o mundo como também participou de modo incisivo e original dos destinos da disciplina na segunda metade do século XX.

"Música, cultura e experiência" é o primeiro texto de Blacking publicado em português.

1. As duas denominaçôes serão empregadas nesta apresentação como sinônimas. John Blacking não fez objeçōes a nenhuma das duas nem deu a entender que uma delas sinalizava a filiaçấo principal à musicologia e a outra à antropologia.
Apareceu originalmente no South African Journal of Musicology, em 1984, com o título "The study of 'music' as cultural system and human capability", e foi incluído na coletânea póstuma editada por Reginald Byron (Blacking, 1995d, p. 223-242). Segundo o editor, o caráter teórico do artigo coloca-o em linha de continuidade com How musical is man? e realiza, parcialmente, o desejo de Blacking de sintetizar seu esforço para pensar antropologicamente a música. Como são poucos os antropólogos que têm contato com seus textos, é necessário falar da originalidade da perspectiva de Blacking, o que faço após resumir informaçôes biográficas que ajudam a situar historicamente o autor ${ }^{2}$.

Uma carreira profissional de pianista parecia ser, até o final dos anos 1940, a opção natural de John Blacking, que nunca deixou de apresentar-se publicamente ao piano e que se iniciou na música na infância, no coro da Catedral de Salisbury. O serviço militar na Malásia, ao fim da Segunda Guerra, despertou-lhe o interesse pela língua e cultura dos nativos e o levou de volta a Cambridge para estudar antropologia social (1950-53). Foi Meyer Fortes quem o aconselhou a buscar orientação para pesquisas etnomusicológicas junto a André Schaeffner, no Museu do Homem (Paris), num estágio de alguns meses. $\mathrm{O}$

2. As informaçôes biográficas apóiam-se basicamente em Blacking (1995b [1973]), na introduçáo de Reginald Byron a Music, culture \& experience (Byron, 1995, p.1-28) e no sítio http://sapir.ukc.ac.uk/ QUB/Introduction/I-Blacking.html, consultado em 03/09/2007. 
retorno à Malásia como conselheiro civil do Exército para assuntos aborígines frustrou a esperança de lançar-se na pesquisa de campo sobre a música balinesa (em Sumatra). Conta Reginald Byron que Blacking se opôs aos planos de deslocamento dos nativos e, tendo que deixar o serviço, encontrou trabalho como professor em Cingapura. Graças a Meyer Fortes - a quem é dedicado How musical is man? -, entrou em contato com Hugh Tracey, musicólogo que dirigia a International Library of African Music, em Roodeport (África do Sul). A instituição produziu uma grande coleção de música africana lançada comercialmente na forma de long-plays. Contratado por Tracey em 1953, Blacking rompeu com a prática de curtas expediçóes destinadas à gravação e inaugurou, naquela instituição, a pesquisa de campo tal como preconizada pelos antropólogos ingleses desde a geração de Malinowski.

Entre 1956 e 1958, viveu entre os venda, com apoio da International Library of African Music, depois da Royal Anthropological Association e da Universidade de Cambridge. A população venda contava, na época, com cerca de 275 mil indivíduos, a maior parte distribuída em aldeias nas montanhas Zoutpansberg do Transvaal, praticando a agricultura e criação de bois e cabras ${ }^{3}$. Uma parte da população trabalhava em caráter temporário em fazendas de proprietários europeus, retornando periodicamente às aldeias. Cerca de $10 \%$ viviam em cidades e haviam sido cristianizados. Freqüentavam as igrejas cristãs de missionários e as separatistas, mantidas por africanos (Blacking, 1995a [1967]). Blacking aprendeu a língua tshivenda e produziu material etnográfico abrangente sobre a organização social e política, a iniciação feminina, os cultos de possessão e das igrejas cristãs separatistas. A tese com a qual obteve o doutorado em antropologia social, entretanto,

3. Ver Blacking (1995a [1967], p. 15). Em How musical is man? ele fala de 300 mil venda. teve como tema as cançóes infantis dos venda (Blacking, 1995a [1967]). As escolas de iniciação feminina e o repertório de cantos, danças e outros exercícios corporais das neófitas foram descritos em quatro artigos, recentemente disponibilizados em CD-ROM juntamente com fotos, filmes e gravaçôes sonoras feitas durante a pesquisa de campo ${ }^{4}$. Em 1958, começou a lecionar na Universidade de Witwatersrand (Joanesburgo), onde permaneceu até 1969, quando deixou a África do Sul em circunstâncias pessoais dramáticas. Suas opinióes sobre as relaçóes raciais faziam de Blacking persona non grata. A gota d'água foi seu relacionamento amoroso com uma mulher indiana (que veio a ser sua segunda esposa). Ambos foram acusados de infringir a proibição às relaçôes inter-raciais e acabaram deixando o país. John Blacking foi para o departamento de antropologia social da Queen's University, em Belfast. No meio acadêmico britânico, foi pioneiro ao conjugar os recursos da dupla formação, em música e em antropologia, para estudar música e dança de uma tribo africana. Uma das conseqüências desse pioneirismo foi sua participação mais ativa nos fóruns de etnomusicologia - entre eles a Society for Ethnomusicology e o International Council for Traditional Music (antigo International Folk Music Council, criado em 1947 no âmbito da UnEsCo) - do que nos da antropologia. Seu nome ficou associado a uma original antropologia da musicalidade - entendida como aptidáo humana para a música e a dança -, mas não é mencionado nas histórias da antropologia britânica em geral (Kuper, 1993). Venda children's songs é, com efeito, um trabalho de análise de 56 cançóes infantis cuja leitura requer não somente conhecimento $\mathrm{da}$ escrita musical e do vocabulário musicológico

4. Editado por Suzel Ana Reily e Lev Weinstock, produzido pelo Departamento de Antropologia Social, Queen's University of Belfast. Disponível em http:// sapir.ukc.ac.uk/QUB/Introduction/TitlePage.html. 
JOHN BLACKING OU UMA HUMANIDADE SONORA E SAUDAVELMENTE ORGANIZADA | I93

como curiosidade por um tema que não estava entre os mais típicos da antropologia africanista (e.g. linhagens, sistemas políticos, rituais, feitiçaria).

Bruno Nettl (1995, p. vii) observa que a influência e respeitabilidade de John Blacking na etnomusicologia não se devem à formalizaçáo de um método - à maneira do que fez Alan Merriam. Contudo, Venda children's songs contém um programa de pesquisa que seu autor chamou de análise cultural da música ${ }^{5}$. Portanto, a observaçáo de Nettl deve-se menos à ausência de um método passível de ser replicado ou testado em outros terrenos empíricos do que ao fato de John Blacking nunca ter escrito um livro de etnomusicologia geral, e sim numerosos textos explorando problemas teóricos específicos, alguns deles de caráter nitidamente desbravador. Por isso também, suas investidas em questôes de fundo, como as da natureza da musicalidade em sua relação com a língua e com a organização social, ou da experiência musical em relaçáo à cognição e à cultura, não se deixam reduzir a um percurso linear ou à identificação incondicional com uma corrente antropológica.

Vinte e dois meses junto aos venda foram a iniciação etnográfica de Blacking e renderam matéria para indagaçóes e análises que se estenderam até os anos 1980. Sua afinidade com a noção de estrutura pode ser percebida na tese sobre as canções infantis e já nesse trabalho ela náo corresponde apenas a relaçóes sociais empiricamente observáveis, senão a algo mais abstrato. Byron (1995, p. 5) reconhece nos primeiros trabalhos de Blacking a marca do funcionalismo e estruturalismo da antropologia britânica, o que inclui Venda children's songs. Embora as referências à noção de estrutura social sejam constantes nesse e em outros trabalhos, assim

5. V. a síntese dos pressupostos da análise cultural da música no artigo de seu aluno José Jorge de Carvalho (2002). como ao livro de Siegfried Nadel The foundations of social anthropology $y^{6}$ o impacto de LéviStrauss e de Noam Chomsky é evidente em How musical is man?, livro que reúne as conferências proferidas a convite da University of Washington em Seattle, em 1973. No mesmo ano, organizou o simpósio sobre antropologia do corpo que pode ser considerado um marco na curva ascendente de sua curiosidade teórica pela natureza da musicalidade, seus fundamentos biossociais e sua relação com a cultura (Blacking, 1977). Mas antes de comentar esses aspectos que conferem originalidade à etnomusicologia de John Blacking, é necessário passar rapidamente pela etnografia venda e outras experiências com a música africana, ponto em que tudo começa.

\section{A análise cultural da música}

"Canções infantis" é um tema incomum de tese em música e ainda mais inusitado na antropologia social. Há algo intrigante nesta escolha de Blacking. Segundo sua explicação, as cançóes eram um pequeno enigma porque não soavam como outros repertórios venda. $\mathrm{A}$ análise musical confirmava que a maior parte delas diferia estilisticamente da música das escolas de iniciação, instituições introduzidas pelos clâs que haviam chegado às montanhas Zoutpansberg ao final do século XVIII e que haviam se tornado os chefes tribais venda ${ }^{7}$. A dança tshikona, por sua vez, universalmente

6. Nadel, que foi colega de Fortes nos seminários de Malinowski, tinha um perfil eclético: escreveu sobre psicologia da música e Ferruccio Busoni, bem como programas de música "exótica" para a Rádio Viena (Kuper, 1993, p. 68).

7. A população venda estava dividida em duas categorias sociais: membros dos clâs comuns, whasiwana (que o autor chama commoners) e membros dos clãs dos chefes, whakololo (chamados por Blacking rulers ou nobles). 
praticada por venda de todos os clãs, revelava ligações estilísticas com a tradição heptafônica dos cantos infantis. Por ser pouco provável que Blacking tenha restringido a análise a um estilo que representasse com mais autenticidade a tradição, a opção pelas cançóes infantis tem outros motivos. Pode estar ligada, talvez, a convicçôes acerca do lugar da música na vida da espécie humana, convicçóes que antecedem os textos que tratam diretamente dessa matéria. Com freqüência, Blacking referiu-se à naturalização da distribuiçấo desigual da musicalidade entre os europeus de sua época e à própria concepção de musicalidade (musical hability), bem diversa daquilo que ele entendia como tal. A pesquisa de campo deu-lhe muitas oportunidades para observar fatos relativos à socialização das crianças venda nas atividades de música e dança. As fotos de seu livro são eloqüentes, assim como seu relato. Ele constatou, por exemplo, que a aquisição de habilidades musicais náo era ditada pela evolução psicomotora dos indivíduos, e sim por normas e crenças acerca dos tipos de música e dança. Somente tornavam-se músicos excepcionais os indivíduos nascidos em determinados grupos sociais, de quem se esperava que produzissem música (Blacking, 1980b, p. 598). Sua aptidão era igual à dos demais venda, mas eles eram socialmente solicitados a desenvolvêlas. As canções infantis apresentavam graus variados de complexidade e não eram introduzidas a cada geração numa ordem linear do simples ao complexo. O pequeno enigma da ligaçáo entre as cançôes infantis e os repertórios de adultos foi resolvido pela análise cultural da música, método que ele sintetizou como análise da experiência cultural subjacente à música que subjaz à música:

My analysis is therefore an attempt to understand the formal, and incidentally the expressive, meaning of music by means of a formal analysis of the cultural experience behind the music behind the music (1995a [1967], p. 197).
Vejamos o sentido desta síntese.

Venda children's songs tem início com a apresentação dos conceitos musicais da tribo. $\mathrm{Na}$ tradição etnográfica de tradução das categorias e sistemas classificatórios nativos, ele discerniu, na terminologia musicológica, nos instrumentos musicais e na música venda propriamente dita, uma organizaçáo tonal, i.e. organização das alturas dos sons e das relaçóes intervalares. O termo muthava designa a fileira de teclas do lamelofone portátil chamado mbila (acionadas pelos dois polegares do instrumentista). Também são chamados pelo mesmo termo muthava cada um dos jogos de 24 ou de 12 tubos de bambu ou junco (os jogos são como uma flauta de pã desmembrada cujos tubos são soprados por indivíduos diferentes, na técnica de alternância). Os venda usam dois jogos de flautas: o de 24 tubos tem as alturas dos sons ordenadas segundo uma escala heptatônica; o de 12 tubos é ordenado segundo uma escala pentatônica. O centro tonal das escalas é chamado phala; o som que conduz de volta à tônica - algo como a sensível da tonalidade no Ocidente - é dito thakhula e situa-se um tom acima do phala. Cada som na escala heptatônica tem um som "acompanhante" uma $5^{a}$ abaixo. Isso significa que cada som forma, com a $5^{\mathrm{a}}$ inferior, um intervalo percebido como consonante. Blacking descobriu, assim, que a música venda é melódica $e$ harmônica, portanto dotada de princípios que organizam as simultaneidades e prescrevem a evitação de alguns intervalos. Com essas evidências, contestou os etnomusicólogos como Hornbostel, que havia avançado a teoria da "pura melodia" dos "primitivos", conceituada como sucessão de sons decorrente das inflexôes da língua, das necessidades de expressão e dos ritmos respiratórios, mas não da racionalização da disposição dos sons conforme consonâncias e dissonâncias.

Os venda entendem que duas melodias são equivalentes se os sons de uma delas mantêm 
JOHN BLACKING OU UMA HUMANIDADE SONORA E SAUDAVELMENTE ORGANIZADA I I95

com os da outra a relação de acompanhantes. Como ele insistiria mais tarde (1995b [1973], p. 99), o princípio que torna duas melodias equivalentes harmônicas é social, do mesmo modo como são de natureza social a distribuição das flautas entre 24 ou 12 indivíduos e a polirritmia dos tambores executados em cânone por três indivíduos. Quando são tocados simultaneamente, os tambores geram padróes que podem soar como uma seqüência ininterrupta de articulaçôes isócronas. Só a observação direta permite entender que, na verdade, os tambores tocam todos um mesmo padrão iâmbico, só que cada um deles está deslocado temporalmente com relação aos outros por ter iniciado depois, em cânone; sua acentuação, portanto, também é deslocada com relação à dos demais. A audição do som dos tambores numa gravação não revelaria o princípio social do cânone, o que mostra que as configuraçôes sonoras podem ser objeto de uma escuta superficial incapaz de discernir o que se passa efetivamente na música. As exigências da atividade musical coletiva e os modos de participar individualmente dos conjuntos são fatores que determinam os sons gerados. Daí a idéia, freqüentemente defendida pelo autor, de que o etnomusicólogo deve estar atento aos fatores não-musicais que geram a música.

Mais tarde, Blacking chamou de estrutura de superfície e estrutura profunda, respectivamente, a música (o fenômeno sonoro) e a música que subjaz à música (sua gramática ou estrutura) (1995b [1973], 1995d). As expressóes chomskyanas, contudo, prestavam-se a um malentendido: era como se ele preconizasse a aplicação de modelos lingüísticos ao estudo da música, quando o que defendia era algo bem distinto - a anterioridade filogenética da dança e da música com respeito à língua (Blacking, 1978, p. 110).

Em Venda children's songs, Blacking discute a análise musical e as análises etnomusicológicas de tradições não-ocidentais. Admite sua dívida para com Alan Merriam (Blacking, 1995c [1971], p. 55), mas certamente não achava satisfatória a idéia de que música é comportamento padronizado e aprendido. A locução "análise cultural da música" não foi tomada de empréstimo a Merriam; foi criada por Blacking por analogia com a "análise funcional" proposta pelo musicólogo Hans Keller. É curioso observar que os musicólogos de inclinação formalista (como H. Schenker), que advogam a análise das obras enquanto objetos autônomos, e os estruturalistas (como N. Ruwet e J.-J. Nattiez) são os que mais interessam a John Blacking quando se trata de forjar instrumentos para descobrir - como ele diz - a música por detrás da música. Mas ele queria ir além da elucidação das estruturas musicais, na direção dos fatores não-musicais que estão na raiz da produção dos sons musicais, o que o distancia dos formalistas e da semiologia estruturalista da música:

...there are many non-musical factors which regulate the structure of the music, and any analysis of the music is as much an analysis of these as it is of the musical sounds that emerge (1995a [1967], p. 195).

\section{Corpo e cognição}

A investigação dos fatores que estão por detrás da superfície sonora prosseguiu nos anos 1970, quando Blacking manifesta interesse explícito pelos processos cognitivos e sociais que constituem a estrutura profunda da música:

The surface structures of Venda music reflect not only the musical conventions of Venda culture which are transmitted from one generation to another, but also cognitive and social processes which are endemic in all aspects of their culture and particularly present in musical activity (Blacking, 1995c [1971], p. 58). 
É importante sublinhar que, para Blacking, cognição é algo que engloba afetos e está intimamente associada a social. Processos cognitivos náo equivalem ao cogito cartesiano, pois estão enredados na natureza social do homem.

Desde a tese sobre as cançôes infantis, Blacking foi um crítico severo das comparaçôes entre sistemas musicais ${ }^{8}$ e da quantificação de traços musicais. Ele próprio experimentou um pouco dos métodos estatísticos em Venda children's songs e sugeriu que seu emprego requeria muita cautela (Blacking, 1995a [1967], p. 173 e ss.). Afinal, o que os etnomusicólogos comparavam eram estruturas superficiais, deixando escapar o nível profundo responsável pela geração dos sons.

Por acreditar na existência desse plano estrutural que se manifesta nas ordenaçôes superficiais do fenômeno sonoro, e que cabe ao etnomusicólogo revelar, Blacking também encarava com ceticismo as afirmaçóes acerca da aculturação musical. Segundo ele, colegas como Nettl e Merriam supunham que há aculturação musical quando um grupo social adota estilos musicais de outro com o qual está em contato. $\mathrm{O}$ caso venda, porém, não corroborava a suposição, pois a adoçáo dos estilos musicais associados às iniciaçóes de meninos $\mathrm{e}$ meninas, e aos cultos de possessão, não afetara o sistema musical, apesar da importante mudança no sistema social. As inovaçóes musicais concomitantes não podiam ser descritas com o conceito de aculturação (Blacking, 1995d, p.149-50).

To qualify as musical change, the phenomena described must constitute a change in the structure of the musical system, and not simply a change within the system (Blacking, 1995d, p. 167).

8. V. a crítica ao método de comparação intercultural de Alan Lomax (Blacking, 1979, p. xviii).
Em compensação, a entrada da música européia levada pelos missionários cristâos foi uma mudança de sistema musical. Encontravam-se, entâo, no seio da população venda, três sistemas: o tradicional, o europeu e um terceiro sincrético que começou a nascer nas igrejas separatistas e nas áreas urbanas (a jive music com violáo e penny whistle) (Blacking, 1980b, p. 600). Por outro lado, por estarem ancoradas em processos cognitivos e sociais, as mudanças musicais podem ser manifestaçôes precursoras de mudanças sociais. Numa curiosa coincidência, Blacking formula, no mesmo ano em que Jacques Attali publica Bruits (1977), a idéia de antecipação na música das transformaçôes na sociedade:

Musical change is important to watch because, owing to the deep-rooted nature of music, it may precede and forecast other changes in society (Blacking, 1995d, p. 172).

Em 1973, Blacking organizou o simpósio sobre antropologia do corpo que gerou a coletânea homônima, publicada alguns anos depois. Num artigo que ele considerou "programático", reivindicou para a antropologia o estudo da estrutura e qualidade dos afetos entendidos como fenômenos simultaneamente internos, subjetivos, e externos, comunicados a outros e capazes de exercer efeitos sobre a cognição e a ação. Tratava-se de explorar os vínculos entre mental e corporal, biológico e cultural, hemisférios direito e esquerdo do cérebro, comunicação verbal e não-verbal, habilidades inatas e adquiridas. Nesse artigo em que expõe sua insatisfação com a dicotomia entre natureza e cultura, retoma a seu favor a idéia de Durkheim da sociedade como um conjunto de forças ativas: são elas a condição de existência dos organismos biológicos humanos. Analogamente, entre as capacidades cognitivas do homem é preciso incluir as que o habilitam às experiências compartilhadas e ao fellow-feeling: 
"...no human can do anything, or even become human, without fellow humans" (Blacking, 1977 , p. 15). Blacking não hesitava, aliás, em falar de empatia e de telepatia, tamanha sua convicção no nexo intersubjetivo e nos limites da concepção do homem como espécie singularizada pela habilidade lingüística. Por isso, é difícil caracterizá-lo como cognitivista, a menos que se faça a ressalva de que cognição e sociedade não podem ser concebidas como duas ordens distintas de fatos humanos:

My concern for an anthropology of the body rests on a conviction that feelings, and particularly fellow-feeling, expressed as movements of bodies in space and time and often without verbal connotations, are the basis of mental life (Blacking, 1977, p. 21).

\section{Protomúsica e protodança constituiçáo do homem}

A interrelação entre música, cognição, afeto, cultura e sociedade foi expressa por Blacking numa retórica de binômios (processos e produtos musicais, estruturas profundas e de superfície, habilidade humana e sistema cultural). Um outro, porém, celebrizou-se como síntese de sua concepção de etnomusicologia: som humanamente organizado e humanidade sonora/saudavelmente organizada?

Os quiasmos dos títulos dos capítulos de How musical is man? são expressivos. O primeiro e o quarto capítulo chamam-se, respectivamente, "som humanamente organizado" e "humanidade sonora/saudavelmente organizada"; o terceiro e o quarto, "a música na cultura e na sociedade" e "a cultura e a sociedade na

9. $\mathrm{Na}$ tradução das expressōes "humanly organized sound" e "soundly organized humanity", perde-se a polissemia da palavra "sound" (como substantivo, significa "som", e como adjetivo, "são" e "seguro"). música”. Embora os críticos enxerguem aí o dilema característico de uma disciplina que não sabe como pensar a música senão nos modos da determinaçáo (pelo social) ou da autonomia (Hennion, 1993), Blacking não tinha qualquer simpatia pelas proposiçôes causais do tipo determinista. São muitos os exemplos de que concebia a relação entre música e sociedade, e a relação entre música e cultura, em termos de afetação mútua de vários fatores. Diz ele a propósito dos venda:

Just as shared social experiences may generate musical experiences, so musical experiences may generate a new kind of social experience. [...] Instead of giving sociological explanations of musical forms, it should be more satisfactory to find structural explanations of both sociological and musical forms (Blacking, 1995c [1971], p. 66 e 68).

Veja-se, por exemplo, seu comentário da eficácia da música na possessão por ancestrais, entre os venda. Por um lado, a descrição adequada do fenômeno tinha que levar em conta as relaçôes sociais (entre vivos, entre vivos e ancestrais), o simbolismo das ações rituais e seu caráter prescritivo. Por outro, havia evidências dos efeitos socializadores e afetivos da música. Ele então pergunta: por que a música leva uma mulher venda ao transe no culto mas não fora dele? Em lugar de responder conforme a sóciológica corriqueira - porque no primeiro caso a música e a dança ocorrem no contexto ritual "certo", sendo, por conseguinte, a atuação do contexto sobre o significado atribuído à música que causa o transe -, ele responde com outra pergunta: não será o contexto social que, no segundo caso, inibe os efeitos sempre muito potentes da música?

Is it the social situation that inhibits the otherwise powerful effects of the music? Or is the music powerless without the reinforcement of a special set 
i98 | Elizabeth Travassos

of social circumstances? (Blacking, 1995b [1973], p. 45).

Ele deixa em aberto o problema, mas não sem dar uma pista sobre sua inclinação:

I cannot answer this, but my own love of music and my conviction that it is more than learned behavior make me hope that it is the social inhibitions which are powerful and not the music which is powerless (Blacking, 1995b [1973], p. 45).

Segundo Byron (1995, p. 15), no final dos anos 1960, quando foram publicados os mais extensos produtos da etnografia venda - Venda children's songs e os artigos de African Studies sobre os rituais de iniciaçáo feminina -, Blacking começou a dar corpo à sua visáo própria da etnomusicologia, que conjugava os aportes da lingüística, do estruturalismo, cognitivismo e biologia. Dela resultou uma definiçẫo original da etnomusicologia como estudo do homem enquanto produtor de música - devendo entender-se música, sempre, como música e dança. A originalidade da definição sobressai quando posta em comparação com as fórmulas que Alan Merriam celebrizou - estudo da música na cultura e estudo da música como cultura - e que centralizaram a discussáo no meio norte-americano. Blacking estava mais interessado nas condiçôes universais de emergência da atividade musical, atada a uma hipotética inteligência musical.

A aposta na busca de estruturas profundas da música radicadas na constituição biopsicológica do homem explica a aversão de Blacking às análises formais do som - análises dos produtos em sua superfície - que apenas parafraseiam ou descrevem. É precisamente na rejeição ao formalismo e ao comparativismo que reside uma de suas importantes contribuiçóes, segundo os etnomusicólogos (Blum, 1992, p. 203; Myers, 1992, p. 10). Entretanto, suas idéias acerca da biogramática (biogrammar) e da dança biossocial - hipoté- ticas protodança e protomúsica que teriam sido decisivas na evolução da espécie - são menos comentadas e talvez encaradas com ceticismo.

Blacking retomou e atualizou uma vertente de interrogaçóes acerca da natureza da musicalidade e seu estatuto próprio, relativamente à língua: qual a razão de ser dessa aptidão da espécie, simbólica sem ser referencial, autônoma face à língua e anterior a ela no sentido filogenético? A resposta não foi buscada unilateralmente na evolução, nem exclusivamente na cognição, nem no social. Ele admitia a impotência do estado atual do conhecimento antropológico diante de sua pergunta. Várias hipóteses alternativas foram, porém, aventadas e examinadas, desde a de expressão e compartilhamento dos afetos - fundamental na constituiçáo de solidariedade grupal, portanto na constituição da sociedade (à maneira de Durkheim) - à produção de estados internos intensos, experiências de transcendência e transe sem os quais o homem não seria como o conhecemos.

Em "The biology of music-making", seu último trabalho publicado, Blacking comenta três hipóteses explicativas da musicalidade que circulam em várias sociedades: a primeira afirma que a música é aprendida, adquirida, portanto social; a segunda diz ser a música capacidade herdada geneticamente, por isso desigualmente distribuída entre os homens; a terceira afirma ser a música herdada geneticamente, tanto quanto a habilidade para a linguagem - portanto, uma parte da biogramática humana e, possivelmente, um sistema modelar primário do pensamento e da comunicação (primary modeling system). Essas três hipóteses - além de outras que atribuem caráter sagrado e origem divina às capacidades musicais - dáo lugar às teorias que se expressam, eventualmente, na forma do mito. A primeira e a segunda sáo características das sociedades modernas industriais. Ele próprio, Blacking, era simpático à terceira, por resistir à idéia de reduzir a musicalidade a um conjunto de padróes de comportamento aprendido: 
JOHN BLACKING OU UMA HUMANIDADE SONORA E SAUDAVELMENTE ORGANIZADA I I99

People's sense of their own musicality is a deeper and more visceral experience than anything that is culturally acquired, such as membership in a particular organization or proficiency in some skill (Blacking, 1992, p. 304).

As condições de florescimento ou inibição da aptidão musical são, contudo, sociais. Dependem das interaçôes, das instituições e de uma seleção de capacidades cognitivas e sensório-motoras. Entretanto, não se trata simplesmente de aumentar a cota da natureza na partilha com a cultura, lançando a música para o campo da biologia e da psicologia, de onde os cientistas sociais a retiraram. Mesmo sendo música e dança um conjunto de experiências corporais, elas não são impulsos, nem reações automáticas. Isso não tem nada a ver com imaginar padrôes e formas sonoras que desencadeiam o estado de transe, nem com a idéia de universalidade de conteúdos musicais específicos, tais como a percepção de consonâncias e dissonâncias em virtude das fraçóes numéricas a que correspondem os intervalos musicais. A inteligência musical ou o sistema modelar primário que dá origem à música e à dança é algo vazio de conteúdo. Sua realização não é necessariamente sonoro-musical, podendo manifestar-se - quem sabe? - na arquitetura, na matemática etc.

Por isso, ainda que não se possam abordar os problemas da semântica e da estética musical independentemente dos sistemas culturais particulares aos quais estão necessariamente atreladas - pois é a ordem cultural que confere valor aos estados corporais, transformando-o metaforicamente em emoçóes, por exemplo -, a musicalidade jaz em outro patamar do humano. Para compreendê-la, Blacking buscava socorro dos psicólogos cognitivistas (John Sloboda), de neurologistas (como Manfred Clynes) e estudiosos da linguagem (E. Lennenberg).
The essence of music is non-verbal and hence cannot be conceived as a product of word-based ideological construction. The varieties of musical thought and practice in the world presuppose innate musical intelligence even though ethnomusicological research has shown that music is a social fact, that musical systems are cultural systems woven into the larger web of the cultures of communities, and that the variety of these symbol systems precludes a universally valid definition of music or universal agreement on what constitutes music as distinct from nonmusic or noise (Blacking, 1992, p. 310).

Entre outras hipóteses, levantava a de ser a inteligência musical uma inteligência para o social que teria desempenhado papel importante na evolução da espécie na direção de formas de vida social complexas. A inteligência musical agrega indivíduos em grupos, coordena ações, integra os hemisférios do cérebro. Em apoio à hipótese do valor evolucionário da música, citava o ensaio de Alfred Schutz sobre a atividade musical conjunta: evidência da capacidade humana de entrar em fluxos intersubjetivos, a música em conjunto supõe uma sintonização mútua (mutual tuning-in) não-verbal cujo entendimento seria de grande valor para a sociologia, já que é quase um paradigma da relação social. Se entendermos como um grupo de câmara coordena sem uso da língua os fluxos temporais internos dos seus membros, entenderemos a relação social e, por conseguinte, o próprio social (Schutz, 1977). Eis, com efeito, um tema caro a John Blacking.

Byron atribui certas inclinaçóes teóricas de Blacking à experiência emocional ímpar de comunhão proporcionada pelo canto coral nas igrejas inglesas. Ele próprio atribuiu sua convicção acerca da universal musicalidade humana à vivência africana. Ambas estão presentes em seus textos, repletos de referências às obras clássicas e modernas da grande tradição 
ocidental e aos exemplos africanos, principalmente venda. Eles reforçam seus argumentos em busca de uma antropologia da música capaz de abranger todos os sons humanamente organizados, de bosquímanos, balineses, bemba, Bach, Beethoven e Bartók. Talvez uma teoria unificada do humano que, ao compreender a natureza das forças musicais que fervilham em nós, possa promover o conhecimento e a transformação das sociedades humanas.

\section{Referências bibliográficas}

ATTALI, Jacques. Bruits: essai sur l'économie politique de la musique. Paris: Presses Universitaires de France, 1977. $301 \mathrm{p}$.

BLACKING, John. The anthropology of the body. London: Academic Press, 1977. 438 p.

"L'homme producteur de musique" (segunda parte), Musique en jeu, 29, 1978, p. 108-116.

"Introduction". In: BLACKING, J.; KEALII-

NOHOMOKU, Joan W. (Eds.). The performing arts: music and dance. The Hague: Mouton, 1979, p. 3-15. Le sens musical. Paris: Minuit, 1980a. 141 p.

"Venda music". In SADIE, S. (Ed.). The new

grove dictionary of music and musicians, v. 19, 1980b, p. 596-602.

"The biology of music-making", in: MYERS,

Helen (Ed.). Ethnomusicology: an introduction. New York: 1992, p. 301-314.

Venda children's songs: a study in ethnomusicologi-

cal analysis. Chicago: The University of Chicago Press, 1995a [1967]. 210 p.

How musical is man? Seattle: University of Washingon Press, 1995b, 5 ed. [1973]. 116 p.
"The problem of musical description". In: BLACKING, J. Music, culture \& experience. Chicago: University of Chicago Press, 1995d [1971], p. 54-72.

Music, culture \& experience. Selected papers of John Blacking. Ed. by Reginald Byron. 1995d. 269 p.

BLUM, Stephen. "Analysis of musical style". In: MYERS, Helen (Ed.). Ethnomusicology: an introduction. New York: W. W. Norton \& Co, 1992, p. 165-218.

BYRON, Reginald. "The ethnomusicology of John Blacking”. In: BLACKING, J. Music, culture \& experience. Chicago: The University of Chicago Press, 1995, p. 1-28.

CARVALHO, José Jorge de. “Estéticas de la opacidad y la transparencia: música, mito y ritual en el culto shangó y en la tradición erudita occidental", Trans, Revista Transcultural de Música, n. 6, 2002. Disponível em: http://www.sibetrans.com/trans/trans6/carvalho.htm.

HENNION, Antoine. La passion musicale. Paris: Métaillié, $1993.406 \mathrm{p}$.

HOOD, Mantle. The ethnomusicologist. New York: McGraw-Hill, 1971. 386 p.

KERMAN, Joseph. Musicologia. São Paulo: Martins Fontes, $1987.331 \mathrm{p}$.

KUPER, Adam. Anthropology \& anthropologists: the modern British school. 3. ed London: Routledge, 1993. $233 \mathrm{p}$.

MERRIAM, Alan. The antrhropology of music. Evanston: Northwestern University Press, 1964. 358 p.

MYERS, Helen. "Ethnomusicology”. In: MYERS, Helen (Ed.). Ethnomusicology: an introduction. New York: W. W. Norton \& Co., 1992, p. 3-18.

NETTL, Bruno. Theory and method in ethnomusicology. New York: Free Press, 1964. 306 p.

SCHUTZ, Alfred. "Making music together". In: DOLGIN, J. Kennitzer, D. S.; SCHNEIDER, D. M. (Eds.). Symbolic anthropology: a reader in the study of symbols and meanings. New York: Columbia University Press, 1977, p. 106-119

\title{
autor Elizabeth Travassos
}

Professora Adjunta do Departamento de Educação Musical/UFRJ

Doutora em Antropologia Social/MN-UFRJ

\author{
Recebido em 21/11/2007 \\ Aceito para publicą̧ão em 22/01/2008
}

